\title{
Moyamoya syndrome concomitant with hyperhomocysteinemia and a Metbylenetetrabydrofolate reductase gene mutation: a case report and brief review
}

\author{
Abreu Montanaro $\mathrm{VV}^{1 *}$, Marinho PB ${ }^{1}$, Uchoa Cavalcanti EB ${ }^{1}$, Ferreira Martins BJA ${ }^{1}$ and Cunha Matta AP ${ }^{2}$ \\ ${ }^{1}$ Neurological Rehabilitation Department, SARAH Network of Rehabilitation Hospitals, Brasília, Brazil \\ ${ }^{2}$ Universidade Federal Fluminense, Rio de Janeiro, Brazil
}

\begin{abstract}
The role of hyperhomocysteinemia and methylenetetrabydrofolate reductase (MTHFR) gene mutation in the pathogenesis of ischemic stroke has been a topic of growing interest. Reports available in literature describe this association, primarily in cases of pediatric stroke.

We report a case of a 23-year-old woman presented to the SARAH Network of Rehabilitation Hospitals with a history of recurrent ischemic strokes during infancy and an etiological diagnosis of Moyamoya syndrome. Evaluation revealed mild elevation of serum homocysteine levels and a homozygous $M T H F R$ gene mutation, no other associated abnormalities were detected.

There is evidence of the presence of these abnormalities in some cases of pediatric ischemic stroke in the clinical setting. Data are limited regarding the role of hyperhomocysteinemia and an MTHFR gene mutation in causing vascular lesions/damage. Further studies involving patients with ischemic stroke (primarily those with arterial occlusion), are warranted to better establish such a correlation.
\end{abstract}

\section{Introduction}

Data available in literature describe an association between hyperhomocysteinemia and a methylenetetrahydrofolate reductase (MTHFR) gene mutation and vascular events [1]. A possible correlation is known to exist between 677TT MTHFR gene polymorphism and the presence of large-vessel lesions [2] and Moyamoya syndrome. However, the correlation between the 677TT gene polymorphism and Moyamoya syndrome is not conclusive [3]. In the present paper, we report the case of a patient who presented with Moyamoya syndrome associated with hyperhomocysteinemia and a MTHFR gene mutation.

\section{Case report}

A 23-year-old Caucasian woman had presented to SARAH Hospital at age 3 with history of 3 ischemic strokes at 10, 12 and 16 months of age, all in the carotid artery topography. Intracranial magnetic resonance angiography revealed bilateral carotid artery occlusion and the presence of increased leptomeningeal collaterals (Figure 1), leading to a diagnosis of Moyamoya syndrome. Infectious and thrombophilic conditions were ruled out. We also ruled out the presence of the human immunodeficiency virus, syphilis, Chagas disease, lupus, antiphospholipid syndrome, protein $\mathrm{C}$ and $\mathrm{S}$ deficiency, prothrombin mutation, antithrombin III deficiency and Factor V Leiden mutation. No cardiac and/or sickle cell disease was detected. She showed a mild elevation of her serum homocysteine levels (19.4 $\mu \mathrm{mol} / \mathrm{L})$, reference range indicating values within $15 \mu \mathrm{mol} / \mathrm{L})$ and a homozygous MTHFR gene mutation (677TT polymorphism). The Ethics Committee of SARAH Hospital approved this case report based on Brazilian regulations.

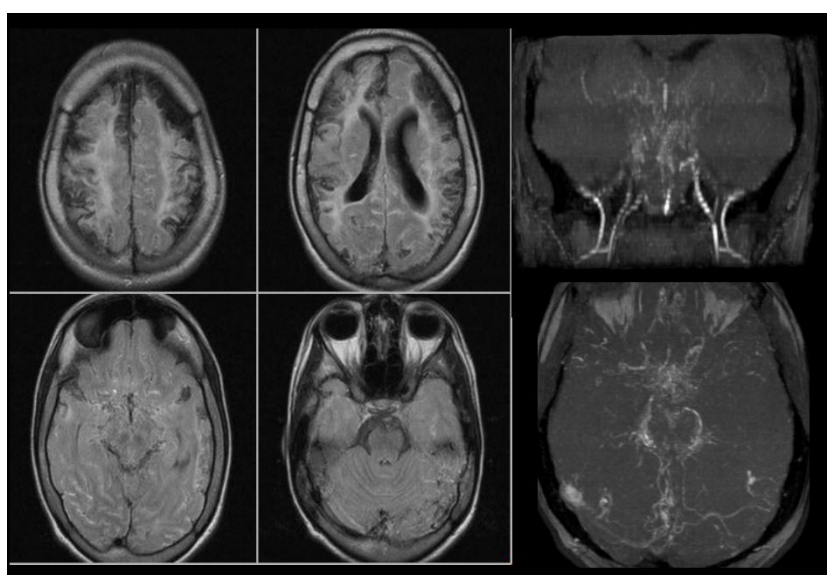

Figure 1. Fluid-attenuated inversion recovery (FLAIR) axial images showing gliosis and cortical necrosis involving the frontal and parietal lobes.

There is subarachnoid hyperintensity observed possibly related to the presence of leptomeningeal collateral vessels.

Time-of-flight-magnetic resonance angiography (TOF-MRA) images: Coronal view: the middle meningeal arteries are observed to be prominent. Internal carotid arteries showing flow interruption in the petrous portion. There is occlusion of the middle cerebral arteries. Hyperintensities corresponding to moyamoya vessels are observed.

Axial view: Moyamoya vessels are identified along the interpeduncular and perimesencephalic cisterns and also along the Sylvian fissure.

*Correspondence to: Abreu Montanaro VV, Neurological Rehabilitation Department, Sarah Hospital, Brasília Brazil, Tel: +55 61 33191111; E-mail: vinicius_montanaro@yahoo.com.br

Received: March 05, 2018; Accepted: March 27, 2018; Published: March 31, 2018 


\section{Discussion}

Recent studies have detected a correlation between even mild degrees of hyperhomocysteinemia concomitant with a MTHFR gene mutation and the presence of small- and large-vessel disease. There is evidence to suggest an association between 677TT polymorphism and the overall incidence of stroke ${ }^{3}$. An association with recurrent ischemic strokes in children has been described concomitant with other thrombophilic conditions or in isolation [4]. The pathomechanisms of vascular lesions/damage leading to arterial occlusion are not well understood. The primary hypotheses reported are endothelial dysfunction, arteriolar hypertrophy, and/or clotting abnormalities [5].

Moyamoya syndrome is characterized by occlusion or stenosis of the supraclinoid portions of the internal carotid arteries and an increase in the leptomeningeal collateral circulation in the territory of the basal ganglia. This disease may occur as an isolated entity or in association with other conditions such as sickle cell disease [6]. Few studies have described an association between this syndrome and multiple prothrombotic factors, hyperhomocysteinemia and a MTHFR gene mutation [7]. Currently, very few reports have demonstrated the occurrence of Moyamoya syndrome concomitant with hyperhomocysteinemia and a MTHFR gene mutation.

The occurrence of this mutation in this case is of unclear significance. However, given the rarity of this condition and lack of studies describing an association (most studies have been performed in children), such findings should prompt further studies in this field to better understand the pathophysiology of this condition for better medical intervention and management of Moyamoya syndrome in the future.

Early detection/diagnosis of this syndrome and the correct identification of associated conditions can ensure prompt administration of medical treatment and thereby prevent/reduce the risk of disabilities related to repeated cerebral ischemia in children.

The role of serum homocysteine levels and a MTHFR gene mutation in the pathogenesis of Moyamoya syndrome remains debatable It is hypothesized that factors predisposing to arterial obstruction, as has been demonstrated in literature, could play a role in precipitating the development of this syndrome. Given the multiple medical conditions associated with Moyamoya syndrome and the potential treatment possibilities for patients presenting with hyperhomocysteinemia, further research is warranted for a better understanding of this condition.

\section{Informed consent}

Written informed consent was obtained from our patient for publication of this case report and all accompanying images

\section{Authors' contribution}

Article conception and drafting of manuscript: Vinícius Viana Abreu Montanaro; Drafting of manuscript and revision: Vinícius Viana Abreu Montanaro, Patrícia Beatriz Marinho, Eduardo Boiteaux Uchoa Cavalcante, Bernardo José Alves Ferreira Martins; Data collection and patient's diagnosis: André Palma da Cunha Matta

\section{Acknowledgement}

The authors would like to thank the SARAH Network of Rehabilitation Hospitals for providing the means and time for the realization of this research paper

\section{Declaration of conflicting interest}

The authors declare that there is no conflict of interest

\section{Funding}

This research/study received no specific grant from any funding agency in the public, commercial, or not-for-profit sectors.

\section{References}

1. Faraci FM, Lentz SR (2004) Hyperhomocysteinemia, oxidative stress and cerebral vascular dysfunction. Stroke 35: 345-347. [Crossref]

2. Luo H, Liu B, Hu J, Wang X, Zhan S, et al. (2014) Hyperhomocysteinemia and methylenetetrahydrofolate reductase polymorphisms in cervical artery dissection: a meta-analysis. Cerebrovas Dis 37: 313-322. [Crossref]

3. Park YS, Jeon YJ, Kim HS, Han IB, Choi JU, et al (2014) The role of methylenetetrahydrofolate reductase $677 \mathrm{C}>\mathrm{T}$ and $1298 \mathrm{~A}>\mathrm{C}$ polymorphisms in moyamoya disease patients. Childs Nerv Syst 30: 1687-1695. [Crossref]

4. Kurnik K, Kosch A, Strater R, Schobess R, Heller C, et al. (2003) Recurrent thromboembolism in infants and children suffering from symptomatic neonatal arterial stroke: a prospective follow-up study. Stroke 34: 2887-2892. [Crossref]

5. McColgan P, Sharma P (2008) The genetics of carotid dissection: meta-analysis of a MTHFR/C677T common molecular variant. Cerebrovasc Dis 25: 561-565. [Crossref]

6. Dobson SR, Holden KR, Nietert PJ, Cure JK, Laver JH, et al. (2002) Moyamoya syndrome in childhood sickle cell disease: a predictive factor for recurrent cerebrovascular events. Blood 99: 3144-3150. [Crossref]

7. Skardoutsou A, Voudris KA, Mastroyianni S, VigiakouE, Magoufis G, et al. (2007) Moyamoya syndrome in a child with pyruvate kinase deficiency and combined prothrombotic factors. J Child Neurol 22: 474-478. [Crossref]

Copyright: (C2018 Abreu Montanaro VV. This is an open-access article distributed under the terms of the Creative Commons Attribution License, which permits unrestricted use, distribution, and reproduction in any medium, provided the original author and source are credited. 